\title{
Double Barrel Fibula Flap with Immediate Dental Implant Insertion for Reconstruction of Mandibular Defects
}

\author{
Almamidou Assoumane ${ }^{1,2}, \mathrm{~K} \mathrm{Liu}^{2}$, Zhe Shao ${ }^{1}$ and ZJ Shang ${ }^{1,2 *}$ \\ ${ }^{1}$ The State Key Laboratory Breeding Base of Basic Science of Stomatology (Hubei-MOST) and Key Laboratory for Oral Biomedicine Ministry of Education, \\ Wuhan University, Wuhan, China
}

${ }^{2}$ Department of Oro-maxillofacial, Head and Neck Oncology, School and Hospital of Stomatology, Wuhan University, Wuhan, China

Submission: February 22, 2018; Published: March 22, 2018

*Corresponding author: Zheng-Jun Shang, Department of Oro-maxillofacial, Head and Neck Oncology, School and Hospital of Stomatology Wuhan University, 237 Luoyu Road, Wuhan 430079 China; Tel: 862787686129; Fax: 862787873260; Email: shangzhengjun@whu.edu.cn

\begin{abstract}
Mandibular defects can be aesthetically and functionally reconstructed by a double-barrel vascularised fibula flap that allowed osseointegrated of the implant. The objective of the current study was to report our experience in using double-barrel fibula flap technique and the advantages of simultaneous insertion of the implant in a free vascularised bone graft. We reviewed 65 patients for reconstruction of mandibular defects using double- barrel fibula flap between August 2014 and August 2016 in our hospital. Of 65 patients, 15 have been reconstructed immediately with double- barrel and insertion of 45 implants in the vascularised bone graft in the same time of surgery. Clinical data were collected by demographic analyses such as age, sex, tumors, site of defects, implants and complications encountered. The mean age of patients with the implant and without were $(51.00 \pm 7.63) /(49.86 \pm 15.79)$ respectively with $\mathrm{P}$ value $(\mathrm{P}=0.90)$. The vascularised free flap was survival, no implant loss was recorded and bone healing achieved good results. Complications of recipients sites due to infections and fistulas were encountered. Mandibular reconstruction using double-barrel fibula flap with immediate implant seemed to be promising and reliable at the same time of operation with the experience of the surgeon.
\end{abstract}

Keywords : Double-barrel fibula flap; Implants; Reconstruction of mandibular defects

\section{Introduction}

The reconstruction of mandibular continuity defects following tumor resection with free vascularised bone flap is considered to be a treatment option [1]. Several techniques have been developed to reconstruct the mandible defect to overcome the height discrepancy between the native mandible and transplanted fibula. Many donor sites, such as iliac crest, fibula, scapula, and radius have been reported recently along with results [2-5]. Each method of reconstruction has its advantages and disadvantages. The iliac crest, radius, and scapula have limited length and width [6]. The fibula flap, first used by Hidalgo in 1989 for reconstruction of continuity of mandibular defects [7]. This flap presents many advantages, such as length of the bony segment, good vascularisation, long vascular pedicle and proper dimension for implant placement [8-10]. However, the disadvantages of this flap do not offer sufficient bone height to restore the alveolar arch when the defect involves a dentate mandible. This can create a discrepancy between the residual mandible and the reconstructed part, causing functional and aesthetic problems. To overcome this problem, we used double - barrel fibula flap technique in our department. The doublebarrel fibula flap produces two vascularised bone struts that may be folded parallel to each other but remains connected by the periosteum and muscle cuff surrounding the peroneal artery and vein. The proximal strut is vascularised in both a periosteal and endosteal blood supply, whereas, the distal strut is vascularised by only periosteal a blood supply.

A rich periosteal blood supply makes fibula to tolerate multiple osteotomies for the recreation of native mandibular contour when using the double-barrel fibula flap. For the restoration of the native mandibular inferior border with the aid of a three-dimensional stereolithographic model is relatively straightforward, the recreation of an accurate interact relationship with the upper barrel is technically challenging. This can be accentuated first by the mobility of the upper barrel up then fixed lower barrel and second by the lingual projection of alveolar process with reference to the mandibular border. 


\section{Global Journal of Otolaryngology}

Inaccuracies in the form of residual crossbite or malocclusion cause great difficulties with subsequent prosthesis fabrication and completion of dental rehabilitation [11]. To resolve this problem simultaneous dental implantation into the free flap guided by testing screws before final bony fixation [12]. The aim of the current study was to report our experience in doublebarrel fibula flap technique and the advantages of immediate dental implantation in the reconstruction of mandibular defects.

\section{Patients and methods}

We reviewed 65 patients for reconstructions of mandibular defects using double-barrel fibula flap and immediate dental implantation between August 2014 and August 2016 in our hospital. Fifty patients underwent only double-barrel fibula flap and fifteen patients with double barrel fibula flap and immediate implantation of 45 implants in transplanted bone. Clinical data was collected by demographic analyses such as ages, sex, tumors, site of defects, implants loading and complications encountered.

\section{Surgical Procedures}

Reconstruction of mandibular defects was performed using a two-team approach: an extirpative surgery team and a reconstructive surgery team. A modified radical neck dissection with resection of malignant tumors or suprahyoid neck dissection with partial mandibulectomy for patients with benign tumors. After completion of resection of mandibular tumors, intermaxillary fixation is performed and the preformed reconstruction plate is fixed to the remaining native mandibular borders. Simultaneously the donor site was harvested by cutting template for the accuracy of reconstruction of the defect and then osteotomized into two segments at least twice the length of the mandibular defect. The two struts are fixed to other with screws and plates and stabilized in the defect using a reconstruction plate. The proximal strut is vascularised by both a periosteal and endosteal blood supply, whereas, the distal strut is vascularised by only a periosteal blood supply. The distal strut of the fibula is partially fixed into the defect with mini plate so that the sites of the osseointegrated dental implant can be planned on the proximal strut of the fibula. The dental implant is implanted in the upper strut; long testing screws with dimension $10 \mathrm{~mm}$ to $12 \mathrm{~mm}$ are connected to the fibula implants construct to confirm that a proper interact relationship with the upper teeth has been reproduced before final osteosynthesis between upper border of the residual mandible and the fibula implant construct.

Finally, the testing screws are replaced with implant cover screws. Microvascular anastomoses were done end to end using the superior thyroid artery or facial artery and external jugular vein as a recipient's vessels after fixing the grafted bone. The donor site defected was closed with full thickness skin grafting and suture was done. Postoperative conventional technique for flap monitoring method was used including clinical examination and observation supplemented beside external Doppler after every 30 minutes for the first 24 hours and then every one hour after for the next 24 hours and every 4 hours in the following days. Postoperatively pharmacological therapy was used when necessary, low dose, low molecular weight heparin. All patients were kept 72 hours in intensive care unit (ICU).

Patients were discharged home and follow- up at 1, 3, 6, 12 and 24 months following implant placement. The clinical evaluation outcomes were performed at one year postoperative which includes: peri-implant health was assessed by the presence of plaque, probing depth measured at mesial, distal, buccal and lingual surfaces, bone resorption based by measuring of the per implant marginal bone loss at the mesial and distal. According to our department guideline criteria for evaluation of reconstruction performance was included: facial profile, occlusal relationship, the opening of mouth and TMJ condition. These criteria were shown (Figures $1 \& 2$ ). Postoperative complications encountered were infections in the recipient site and fistula, appropriate therapy was provided by debridement and antibiotics based on positive cultures. In addition, postoperative nursing care was given to patients with meticulous cleaning the infected site.

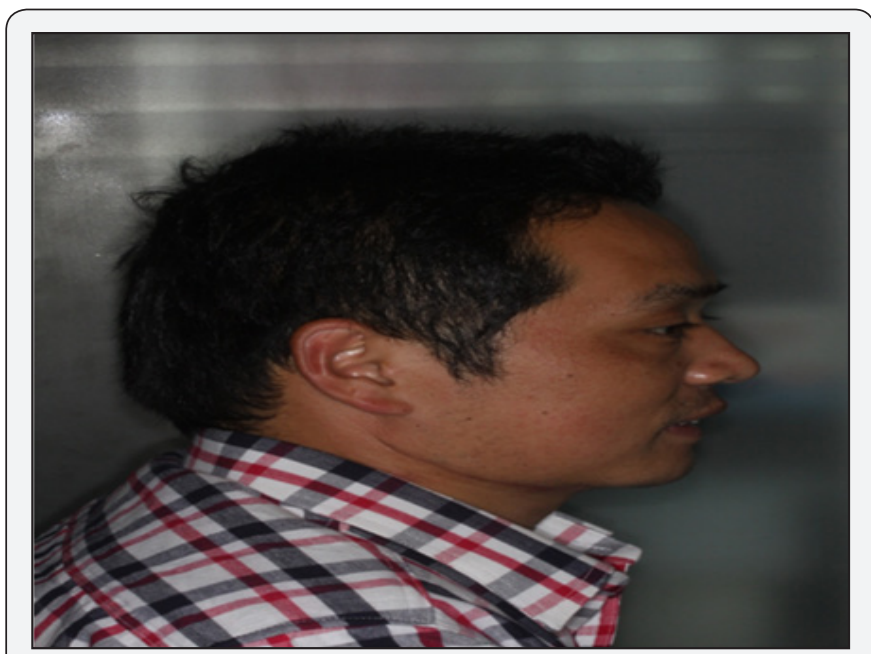

Figure 1: Postoperative profile view of patient treated with double-barrel flap and insertion of implants.

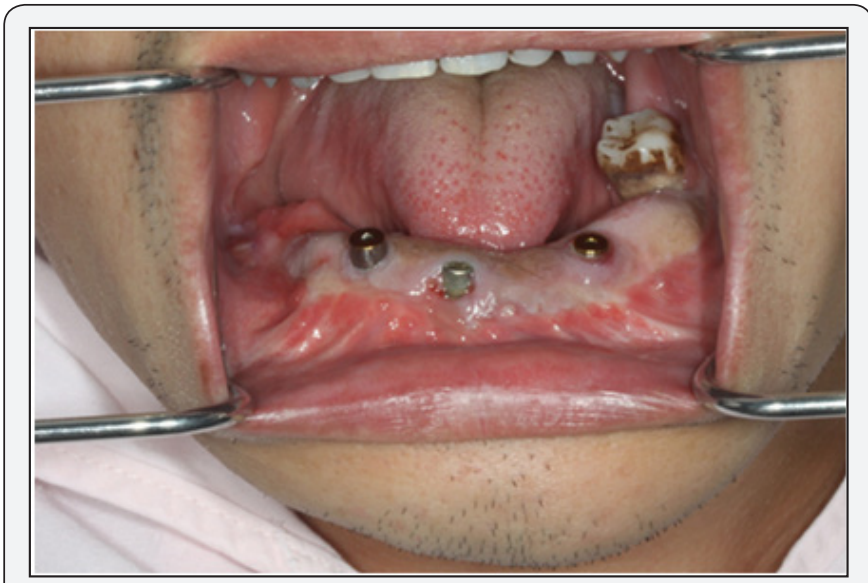

Figure 2 : Intraoral view of patient with Peri-implant soft tissue healing well and stability of implants one year postoperative. 


\section{Global Journal of Otolaryngology}

\section{Statistical analysis}

Data was analysed by using SPSS (SPSS. In Chicago II USA), mean (SD) of patients was obtained for age, sex, sites of defects, implants inserted. Each patient was assessed for bony and soft tissue healing at reconstruction site, the stability of implants and the peri- implants bone loss following functional loading. A t-test of significance was set at $P$ value $<0.05$. There was no significant difference between the independent variables (sites of defects, implants inserted, age, and sex) and independent variables (days staying in hospital).

\section{Results}

We treated 65 patients with tumors and traumatic defects of mandible using double- barrel fibula flap with immediate implant in a free vascularised bone graft. There were 50 patients who underwent double-barrel fibula flap only and 15 patients with double-barrel fibula and immediate insertion of 45 implants in reconstructed site of defects. The mean age of patients underwent double-barrel fibula flap was $49.86 \pm 15.79$, while those who underwent double-barrel and implants simultaneous was $51.00 \pm 7.63$. The indication for resection of mandibular surgery were: Squamous cell carcinoma $(n=20)$; ameloblastoma $(n=16)$; keratocystic odontogenic tumor $(n=9)$; ossifyingfibroma $(\mathrm{n}=4)$; Osteomyelitis $(\mathrm{n}=3)$; radionecrosis $(\mathrm{n}=2)$; Vascular malformation $(\mathrm{n}=2)$; adenoidcysticcarcinoma $(\mathrm{n}=1)$; lymphoma $(\mathrm{n}=1)$; $\operatorname{sarcoma}(\mathrm{n}=1)$; myoepithelioma $(\mathrm{n}=1)$; recurrence of ameloblastoma $(n=1)$; recurrence of adenoid cystic carcinoma $(n=1)$; recurrence of squamous cell carcinoma $(n=1)$ and traumatic defects $(n=2)$. The sites of defects of mandible were located in symphysis $(\mathrm{n}=20)$; symphysis \& parasymphysis $(n=19)$ and parasymphysis \& body of mandible $(n=26)$ (Table 1$)$. All of defects were reconstructed using two segments (doublebarrel) of fibula bone.

Table 1: Personnel details and diagnoses of patients treated with Double-barrel fibular flap and immediate dental implant insertion for reconstruction of mandibular defects.

\begin{tabular}{|c|c|c|c|c|}
\hline $\begin{array}{c}\text { Characteristic of } \\
\text { Patients }\end{array}$ & $\begin{array}{l}\text { DBF } \\
\text { Flap }\end{array}$ & $\begin{array}{l}\text { Implant } \\
\text { Inserted }\end{array}$ & $\chi^{2}$ & $\mathbf{P}$ \\
\hline \multicolumn{5}{|l|}{ Sex } \\
\hline male & 28 & 10 & & \\
\hline female & 22 & 5 & 0.541 & 0.558 \\
\hline \multicolumn{5}{|c|}{ Mandibular defects } \\
\hline Symphysis & 13 & 7 & & \\
\hline Symphysis+parasymphysis & 18 & 1 & & \\
\hline Parasymphysis+body & 19 & 7 & 5.49 & 0.069 \\
\hline \multicolumn{5}{|c|}{ Diagnosis } \\
\hline AMELOBLASTOMA & 12 & 4 & & \\
\hline KCOT & 6 & 3 & & \\
\hline SCC & 14 & 6 & & \\
\hline $\begin{array}{c}\text { Recurrence of } \\
\text { Ameloblastoma }\end{array}$ & 0 & 1 & & \\
\hline OSSIFYING FIBROMA & 4 & 0 & & \\
\hline
\end{tabular}

\begin{tabular}{|c|l|l|l|l|}
\hline Traumatic Defect & 1 & 1 & & \\
\hline OSTEOMYELITIS & 3 & 0 & & \\
\hline Radionecrosis & 2 & 0 & & \\
\hline ACC & 1 & 0 & & \\
\hline Lymphoma & 1 & 0 & & \\
\hline Sarcoma & 1 & 0 & & \\
\hline Vascular malformation & 2 & 0 & & \\
\hline Recurrence of ACC & 1 & 0 & & \\
\hline Recurrence Of SCC & 1 & 0 & & \\
\hline Myoepithelioma & 1 & 0 & 9.656 & 0.865 \\
\hline
\end{tabular}

\begin{tabular}{|c|c|c|c|}
\hline \multirow{2}{*}{ Variables } & not & \multicolumn{2}{c|}{ Implant Insertion } \\
\cline { 2 - 4 } & \multicolumn{2}{|c|}{$(x \pm s)$} & P \\
\cline { 2 - 4 } & $49.86 \pm 15.79$ & $51.00 \pm 7.63$ & 0.907 \\
\hline Ages & $19.26 \pm 5.14$ & $17.47 \pm 3.44$ & 0.302 \\
\hline Days & $0.00 \pm 0.00$ & $4.33 \pm 0.90$ & 0 \\
\hline $\begin{array}{c}\text { number of } \\
\text { implant }\end{array}$ &
\end{tabular}

Abbreviations: KCOT: Keratocystic Odontogenic Tumor; SCC: Squamous Cell Carcinoma; ACC: Adenoid Cystic Carcinoma

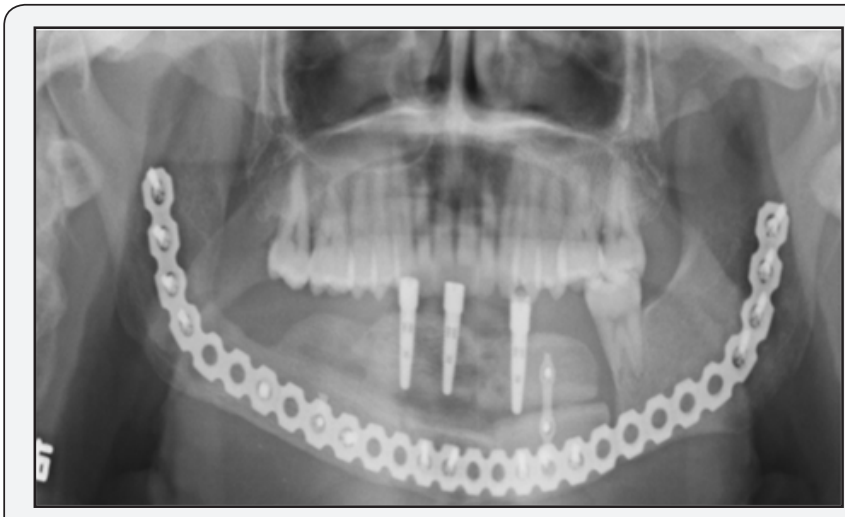

Figure 3 : Panoramic view of patient treated with double-barrel fibula flap with insertion of implants at the time of reconstruction, shown stability of implant and marginal bone was small in one year.

The clinical evaluation of peri-implants soft-tissues was included periodontal indices such as probing pocket depth at mesial / distal and buccal / lingual surfaces of implants. Radiographic evaluation of bone loss was done using panoramic $\mathrm{X}$-rays to assess post-implant insertion marginal bone loss at mesial and distal surfaces of the implant (Figure 3). Most implants with the marginal bone loss after the first year and not caused any major clinical problem. There was no clinical or radiographic evidence of failure during the osseointegration process of 45 implants. The mean (SD) of 15 patients who underwent implant loading was $4.33 \pm 0.90 \mathrm{~mm}$; with no implant loss. The implants with marginal bone loss and probing pocket depth during two years of following- up were done (Table 2). The mean peri-implant bone loss of $0.15 \pm 0.09 \mathrm{~mm}$ at the mesial surfaces and $0.14 \pm 0.08 \mathrm{~mm}$ at distal surfaces, with the mean of 


\section{Global Journal of Otolaryngology}

probing pocket depths, were $2.86 \pm 0.71 \mathrm{~mm}$ at mesial surface; $2.46 \pm 0.44 \mathrm{~mm}$ at distal surface, $2.6 \pm 0.66 \mathrm{~mm}$ at buccal surface and $2.5 \pm 0.53$ at lingual surface showed that the presence of marginal bone loss of a few millimeters was in most cases proved quite unrelated to long-term implants problems and implants stability is clinical manifestation of successful implant integration, whereas mobility is a sign of implant failure.

Table 2: Implants with marginal bone loss and probing pocket depth of 15 patients underwent double fibula flap and insertion of implants during two years of following up.

\begin{tabular}{|c|c|c|c|c|c|}
\hline $\begin{array}{c}\text { Case } \\
\text { No }\end{array}$ & $\begin{array}{c}\text { No of } \\
\text { Implants }\end{array}$ & Sites of implants & $\begin{array}{c}\text { Marginal bone loss(mm) } \\
\text { Mesial/Distal }\end{array}$ & $\begin{array}{c}\text { Probing pocket Depth(mm) } \\
\text { Mesial/Distal }\end{array}$ & Buccal/Lingual \\
\hline 1 & 3 & 333435 & $0.1 / 0.1$ & $2.0 / 2.5$ & $2.0 / 2.0$ \\
\hline 2 & 3 & 434445 & $0.1 / 0.1$ & $3.0 / 2.0$ & $3.0 / 2.5$ \\
\hline 3 & 3 & 333435 & $0.0 / 0.0$ & $3.0 / 3.0$ & $2.0 / 2.0$ \\
\hline 4 & 3 & 434445 & $0.1 / 0.2$ & $4.0 / 2.5$ & $2.0 / 3.0$ \\
\hline 5 & 2 & 3233 & $0.2 / 0.1$ & $2.0 / 2.5$ & $3.0 / 3.0$ \\
\hline 6 & 3 & 323334 & $0.1 / 0.3$ & $3.0 / 2.5$ & $4.0 / 2.0$ \\
\hline 7 & 4 & 31323334 & $0.3 / 0.1$ & $4.0 / 2.0$ & $3.0 / 3.0$ \\
\hline 8 & 3 & 414243 & $0.2 / 0.2$ & $3.0 / 2.5$ & $3.0 / 3.0$ \\
\hline 9 & 3 & 424344 & $0.1 / 0.1$ & $2.0 / 2.0$ & $2.0 / 2.0$ \\
\hline 10 & 3 & 323334 & $0.3 / 0.3$ & $2.5 / 2.5$ & $3.0 / 2.5$ \\
\hline 11 & 3 & 313233 & $0.1 / 0.1$ & $2.0 / 2.0$ & $3.5 / 3.0$ \\
\hline 12 & 3 & 333435 & $0.1 / 0.1$ & $3.0 / 3.5$ & $2.0 / 2.0$ \\
\hline 13 & 3 & 424344 & $0.1 / 0.1$ & $3.0 / 3.0$ & $2.5 / 3.0$ \\
\hline 14 & 3 & 414243 & $0.3 / 0.2$ & $4.0 / 2.5$ & $2.0 / 2.0$ \\
\hline 15 & 3 & 333435 & $0.2 / 0.1$ & $2.86 \pm \mathbf{0 . 7 1 / 2 . 4 6 \pm 0}$ & $\mathbf{2 . 6 \pm 0 . 6 6 / 2 . 5 \pm 0 . 5 3}$ \\
\hline Mean & & & $\mathbf{0 . 1 5 \pm 0 . 0 9 / 0 . 1 4 \pm 0 . 0 8}$ & & \\
\hline SD) & & & & & \\
\hline
\end{tabular}

In this study, the initial marginal bone loss was $0.15 \pm 0.09 \mathrm{~mm}$ mesial and $0.14 \pm 0.08 \mathrm{~mm}$ distal with their definition probing pocket depth at mesial/distal were $2.86 \pm 0.71 \mathrm{~mm} / 2.46 \pm 0.44 \mathrm{~mm}$ and buccal /lingual were $2.6 \pm 0.66 \mathrm{~mm} / 2.5 \pm 0.13 \mathrm{~mm}$. This result shows no difference in bone loss between the different implants inserted in 15 patients in immediate dental implantation in two years follow-up. There was no bone resorption around implants, no bleeding in probing, periodontal tissues were healthy and the aesthetic result was acceptable.

\section{Discussion}

Single fibula flap had provided vertical height discrepancy of the neomandible and difficulty in implant insertion for immediate reconstruction of mandibular defects. There are many methods to increase the height of the fibula but in the current study, we used double-barrel fibula flap to overcome this problem. However, double-barrel fibula flap with immediate implant was not a new technique. There are few articles describing this technique in mandibular reconstruction with the anterior segment and body defects $[13,14]$.

The advantage of insertion of implants into free vascularised bone grafts for mandibular reconstruction included:

a) Reduction of the number of surgical procedures.

b) Access to the bone at the time of reconstruction. c) Immediate assessment of alveolar ridge relationships for accurate positioning of the implant-fibula construct.

d) To obtain adequate dental ridge relationships and avoid inclination of the implants, to achieve earlier dental rehabilitation and occlusion.

Simultaneous techniques, allowed the patient to avoid additional surgical procedures for delayed implant placement, time and number of anesthetic events were reduced and cost of admission to the hospital can also reduce. In addition psychological and aesthetic benefit to the patient who underwent implant at the time of reconstruction of defects. With experience, the double-barrel fibula flap offers more advantages, since the bicortical structure of the double-barrel fibula graft provides excellent conditions for primary stability of dental implants. Implantation of the dental on transplanted bone is clearly reliable with the experiences of microsurgical teams [15]. This allowed insertion of implants and restoration of aesthetic facial contour. Some authors reported for bone consolidation and mucosal healing seemed to wait three months for the requirement in terms of prosthetic results. In addition, when the bone healing and mucosa had healed it will be the ideal time to place the implants directed by the surgical guided and the definitive occlusal relation [16]. In this study, we placed implants in 15 patients according to the sites of defects in the same days of reconstruction using double-barrel flap and implants stability 


\section{Global Journal of Otolaryngology}

were successful after 24 months follow-up, the peri-implant soft tissues outcomes were healing well and total implant marginal bone loss was only $0.15 \mathrm{~mm}$.

Implants stability is the clinical manifestation of successful implant integration, whereas mobility is a sign of implant failure [17]. Although Chiapasco \& Gatti [18] reported in a case series that due to excellent primary stability for implants placed in grafted fibula bone; immediate loading of the implants was achievable. However, immediate placement of implants may be compromised bone viability, lengthen the operation procedure or result in implant failure or malposition [19]. Double-barrel fibula flap with greater suitability for osseointegrated implant than the iliac bone graft shown as to be a safe and reliable method to esthetically and functionally reconstruction of mandibular defects following tumor resection. However, this technique in case of large defects more than $10 \mathrm{~cm}$ cannot be used because the fibula length usually required is $24 \mathrm{~cm}$ during bone harvest, which would in higher donor site morbidity risk. Horiuchi et al. [20] applied this technique to reconstruction of the hemi-mandible using a length of up to approximately $14 \mathrm{~cm}$.

Although Guerra et al. [21] introduced a modification of the double-barrel technique in the reconstruction of mandibular body and ramus. we used this previously technique to reconstruct the symphysis, para symphysis, and body of the mandible and restore mandibular height especially at the anterior segment with implantation of 45 implants in 15 patients were successfully achieved with peri - implants soft tissues healing well without bleeding in the probing. However there was no statistical result in present study because for the sample size was small and may not have had sufficient power to give more valuable results. This study was not a randomized, we only described the previously technique with experience of the author. Many studies have reported improving the peri-implant tissue and the height of the reconstructed bone by either double barreling of the fibula or even vertical distraction of the fibula may lead to favorable periimplant soft tissue outcomes [22].

A disadvantage of this study is the limited post- rehabilitation follow-up time period because some patient went to others hospital for implant rehabilitation prosthesis. Meticulous longterm follow- up is required to determine the feasibility of different soft tissue management techniques as well as determining the success of the treatment. However we described this technique with a few patients because most of the patients came to the rural area with social-economic impact, they preferred to treat the defects without implant. For future research, we wish to use a big size of patients to compare the results of finding.

\section{Conclusion}

Mandibular reconstruction using double-barrel fibula flap with immediate implant insertion seemed to be promising and reliable at the same time of operation with the experience of the surgeon.

\section{References}

1. Foster RD, Anthony JP, Sharma A, Pogrel MA (1999) Vascularized bone flaps versus nonvascularized bone grafts for mandibular reconstruction: an outcome analysis of primary bony union and endosseous implant success. Head Neck 21: 66-71.

2. Taylor GI (1982) Reconstruction of the mandible with free composite iliac bone grafts. Ann Plast Surg 9: 361-376.

3. Hidalgo DA, Row A (1982) A review of 60 consecutive fibulas free flap mandible reconstruction. Plast Reconstr Surg 96: 585-596.

4. Swartz WM, Banis JC, Newton ED, Ramasastry SS, Jones NF, et al. (1986) The osteocutaneous scapular flap for mandibular and maxillary reconstruction. Plast Reconstr Surg 77: 530-545.

5. Swanson E, Boyd JB, Manktelow RT (1990) The radial forearm flap: reconstructive applications and donor site defects in 35 consecutive patients. Plast Reconstr Surg 85: 258-266.

6. Helman JI, Blanchaert RH (2004) Microvascular free tissues transfer. In Miloro M, Ghali GE, Larsen PE, Waite PD (Eds.) Petersons principles of oral and maxillofacial surgery. Decker, London, England, pp. 803-819.

7. Hidalgo DA (1989) Fibula free flap a new method of mandible reconstruction. Plast Reconstr Surg 84: 71-79.

8. Frodel J, Funk GF, Capper DT, Fridrich KL, Blumer J (1993) Osteointegrated implants: a comparative study of bone thickness in four vascularized bone flaps. Plast ReconstrSurg 92: 449-455.

9. Moscoso JF, Keller J, Genden E, Weinberg H, Biller HF, et al. (1994) Vascularized bone flaps in oromandibular reconstruction. A comparative anatomic study of bone stock from various donor sites to assess suitability for endosseous dental implants. Arch Otolaryngology Head Neck Surg 120: 36-43.

10. Yim KK, Wei FC (1994) Fibula osteoseptocutaneous flap for mandible reconstruction. Microsurgery 15: 245-249.

11. Kramer F, Kempf R, Bremer B (2005) Efficiency of dental implants placed into a fibula free flap for orofacial reconstruction. Clin Oral Implants Res 16: 80-88.

12. Chang YM, Chama JS, Wei FC, Shen YF, Chan CP, et al. (2003) Use of waxing screws for accurate primary placement of endosteal implants in the vascularized fibular bone reconstructed mandible. Plast Reconstr Surg 111: 1693-1696.

13. Yan Ming, chi ying Tsai, Fu chan Wei (2008) one stage Double Barrel Fibula Osteoseptocutaneous flap and immediate Dental implants for functional and aesthetic reconstruction of segmental mandibular defects . J plastic reconstructive Surgery 122(1): 43-145.

14. (2016) Mandibular reconstruction using the free vascularised fibula graft: An overview of different modifications. Archives of plastic surgery 43: 1 .

15. Chiapasco M, Biglioli F, Antelitanol, Romeo E, Brusatir (2006) Clinical outcome of dental implants placed in fibula free flap used for reconstruction of maxillo-mandibular defects following ablation for tumors or osteoradionecrosis. Clin Oral Implants 17: 220-228.

16. Jagdee S, Chana (2004) Segmental mandibulectomy and immediate free fibula osteoseptocutaneous flap reconstruction with endosteal implants: an ideal treatment method for mandibular ameloblastoma. Plast Reconstr Surg 113(1): 80-87.

17. Albrektsson T, Zarb G, Worthington P, Eriksson RA (1986) The long term efficacy of currently used dental implants a review and proposed criteria for success. Int J Oral Maxillofac Implants 1: 11-25.

18. Chiapasco, M Gatti (2004) Immediate loading of dental implants placed in revascularized fibular free flaps: a clinical report on 2 consecutive patients. In J of Oral Maxill implants 19: 906-912. 
19. Disa J, Hidalgo D, Cordeiro P, winter R, Thaler H (1999) Evaluation of bone height in the osseous free flap Mandible reconstruction: an indirect measure of bone mass. Plastic Reconstruction Surgery 103: 1371-1377.

20. Horiuchi K, Hattori, An Inada I (1995) Mandibular reconstruction using the double barrel fibula graft. Microsurgery 46: 450-454.
21. Guerra MF, Gas LN, Campo FJ (2000) the partial double barrel free vascularised fibular graft: A solution for long mandibular defects. Plast Reconstr Surg 105(5):1902-1903.

22. Chang YM, Wallace CG, Hsu YM, Shen YF, Tsai CY (2014) Outcome of osseointegrated dental implants in double-barrel vertically distracted fibula osteoseptocutaneous free flaps for segmental mandibular defect reconstruction. Plast Reconstr Surg 134: 1033-1043.

\section{Your next submission with Juniper Publishers will reach you the below assets}

- Quality Editorial service

- Swift Peer Review

- Reprints availability

- E-prints Service

- Manuscript Podcast for convenient understanding

- Global attainment for your research

- Manuscript accessibility in different formats

( Pdf, E-pub, Full Text, Audio)

- Unceasing customer service

Track the below URL for one-step submission https://juniperpublishers.com/online-submission.php 